\title{
Correction to: Functionality of circuit via modern fractional differentiations
}

\author{
Kashif Ali Abro ${ }^{1}$ (1) $\cdot$ Ali Asghar Memon ${ }^{2} \cdot$ Anwar Ahmed Memon $^{2}$
}

Published online: 10 January 2019

(C) Springer Science+Business Media, LLC, part of Springer Nature 2019

\section{Correction to: Analog Integrated Circuits and Signal Processing} https://doi.org/10.1007/s10470-018-1371-6

The article "Functionality of circuit via modern fractional differentiations", written by Kashif Ali Abro, Ali Asghar Memon and Anwar Ahmed Memon, was originally published electronically on the publisher's internet portal (currently SpringerLink) on November 2018 with open access.

With the author(s)' decision to step back from Open Choice, the copyright of the article changed on December 2018 to Springer Science+Business Media, LLC, part of Springer Nature 2018 and the article is forthwith distributed under the terms of copyright.

The original article can be found online at https:// doi.org/10.1007/s10470-018-1371-6.

\section{Kashif Ali Abro}

kashif.abro@faculty.muet.edu.pk

1 Department of Basic Sciences and Related Studies, Mehran University of Engineering and Technology, Jamshoro, Pakistan

2 Department of Electrical Engineering, Mehran University of Engineering and Technology, Jamshoro, Pakistan 